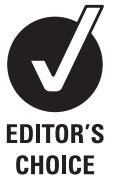

See Editorial, p189

${ }^{1}$ Population Genetics and Gene Therapy, National Heart and Lung Institute, Imperial College, London, UK ${ }^{2}$ Royal Brompton \& Harefield NHS Foundation Trust, London, UK

\section{Correspondence to}

Dr Leyla Osman, Department of Physiotherapy, St Thomas' Hospital, Westminster Bridge Road, London SE1 7EH, UK; leyla.osman@gstt.nhs.uk

Received 12 January 2009 Accepted 31 July 2009 Published Online First 23 August 2009

\section{UNLOCKE}

This paper is freely available online under the BMJ Journals unlocked scheme, see http:// thorax.bmi.com/site/about/ unlocked.xhtml.

\title{
Short-term comparative study of high frequency chest wall oscillation and European airway clearance techniques in patients with cystic fibrosis
}

\author{
Leyla P Osman, ${ }^{1,2}$ Michael Roughton, ${ }^{2}$ Margaret E Hodson, ${ }^{1,2}$ Jennifer A Pryor ${ }^{2}$
}

\begin{abstract}
Background High frequency chest wall oscillation (HFCWO) is standard treatment for airway clearance in the USA and has recently been introduced in the UK and Europe. There is little published research comparing HFCWO with airway clearance techniques (ACTs) frequently used in the UK and Europe. The aim of this study was to compare the short-term effects of HFCWO with usual ACTs in patients with cystic fibrosis hospitalised with an infective pulmonary exacerbation. Methods A 4-day randomised crossover design was used. Patients received either HFCWO on days 1 and 3 and usual ACTs on days 2 and 4 or vice versa. Wet weight of sputum, spirometry and oxygen saturation were measured. Perceived efficacy, comfort, incidence of urinary leakage and preference were assessed. Data were analysed by mixed model analysis.
\end{abstract}

Results 29 patients (72\% male) of mean (SD) age 29.4 (8.4) years and mean (SD) forced expiratory volume in $1 \mathrm{~s}$ $\left(\mathrm{FEV}_{1}\right)$ percentage predicted $\left(\mathrm{FEV}_{1} \%\right) 38$ (16.7) completed the study. Significantly more sputum was expectorated during a single treatment session and over a $24 \mathrm{~h}$ period (mean difference $4.4 \mathrm{~g}$ and $6.9 \mathrm{~g}$, respectively) with usual ACTs than with HFCWO $(p<0.001)$. No statistically significant change in $\mathrm{FEV}_{1} \%$ or oxygen saturation was observed after either HFCWO or usual ACTs compared with baseline. 17 patients (55\%) expressed a preference for their usual ACT.

Conclusions During both a finite treatment period and over $24 \mathrm{~h}$, less sputum was cleared using HFCWO than usual ACT. HFCWO does not appear to cause any adverse physiological effects and may influence adherence.

\section{INTRODUCTION}

The last four decades have seen improved survival in patients with cystic fibrosis (CF). The latest figures estimate the median life expectancy of individuals with CF born in 2000-3 to be approximately 40 years. ${ }^{1}$ Respiratory failure is the major cause of morbidity and mortality in those with CF. ${ }^{2}$ Accumulation of secretions in the CF airway precipitates chronic infection, causing a progressive deterioration in lung function and eventually respiratory failure and death. ${ }^{3}$ Airway clearance techniques (ACTs) are an essential component of the management of patients with CF and are considered standard care. ${ }^{4}$ There is a range of ACTs which augment the normal mucus clearance mechanisms of the lung to facilitate expectoration. These techniques generally aim to promote secretion clearance by altering airflow and mucus viscosity.
Typically, high frequency chest wall oscillation (HFCWO) produces compression of the chest wall via an inflatable jacket linked to an air pulse generator. The generator delivers an intermittent flow of air into the jacket which rapidly compresses and releases the chest wall at a variety of frequencies. Consequently, an oscillation in airflow within the airways is achieved. HFCWO has been shown to enhance central and peripheral mucus clearance. ${ }^{5}$ A number of underlying mechanisms have been hypothesised including increased airflow-mucus interaction causing a reduction in viscolelasticity, production of an expiratory airflow bias which promotes a cephalad movement of mucus and the enhancement and stimulation of ciliary activity. ${ }^{67}$ Published short-term evidence has demonstrated increased sputum clearance and improved pulmonary function with HFCWO compared with no treatment. ${ }^{8}$ This and other studies have also compared HFCWO with alternative ACTs. Some have demonstrated increased sputum clearance with HFCWO compared with postural drainage and percussion $(\mathrm{PD} \& \mathrm{P}) .^{9-11}$ Others found no significant difference in sputum clearance between HFCWO and PD\&P, 81213 positive expiratory pressure (PEP), ${ }^{8}$ high frequency oral oscillation ${ }^{13}$ or intrapulmonary percussive ventilation. ${ }^{14}$ Furthermore, some of these studies found no differences in efficacy related to pulmonary function between HFCWO and PD\&P, 81213 PEP, 815 oscillating positive expiratory pressure (Flutter, manufactured by Axcan Scandipharm Inc, Birmingham, AL, USA) ${ }^{16}$ and high frequency oral oscillation. ${ }^{13}$ One study reported an improved outcome in forced expiratory volume in $1 \mathrm{~s}\left(\mathrm{FEV}_{1}\right)$ in the longer term using HFCWO compared with PD\&P. ${ }^{17}$

Few trials have compared HFCWO with alternative ACTs which are commonly used in the UK and Europe by individuals with CF. Phillips et al ${ }^{18}$ compared HFCWO (using the Hayek Cuirass) with the active cycle of breathing techniques (ACBT) in hospitalised paediatric patients. Significantly more sputum was cleared with the ACBT. The authors concluded that HFCWO was not an effective airway clearance treatment for children with CF. It is difficult to compare this study directly with those above, as the Hayek Cuirass machine has a different operating mode to the inflatable vest system.

A series of Cochrane systematic reviews have found that no one ACT is superior in terms of respiratory function and efficacy. ${ }^{19}$ Of a number of published studies on HFCWO, only two were deemed of sufficient quality to be included in these randomised control trial systematic reviews. ${ }^{8} 12$ 
HFCWO is widely used in the USA where it is considered standard care in $\mathrm{CF}^{20}$ It has recently been introduced to the UK and Europe, where the mainstay of care for airway clearance in $\mathrm{CF}$ is the ACBT, autogenic drainage (AD) and other airway clearance regimens using small devices. ${ }^{4}$ In the USA these techniques and devices tend to be considered adjuncts, with PD\&P and HFCWO remaining the most common ACTs. ${ }^{20}$ While there is a body of evidence which equates HFCWO and PD\&P, there is a need for further trials to compare HFCWO with alternative ACTs to provide a more relevant evidence base for HFCWO in the UK and Europe.

The aim of the present study was to compare the short-term effects of HFCWO with patients' usual ACTs in those with CF admitted to hospital with an acute exacerbation of pulmonary infection. The hypothesis was that HFCWO was superior to patients' usual ACTs.

\section{METHODS}

\section{Study participants}

All patients admitted to hospital who met the entry criteria were invited to participate in the study. The inclusion criteria were a diagnosis of CF (established by genotype or sweat sodium $>70 \mathrm{mmol} / \mathrm{l}$ or sweat chloride of $>60 \mathrm{mmol} / \mathrm{l}), \mathrm{FEV}_{1} \geq 20 \%$ predicted, age $\geq 16$ years and an infective pulmonary exacerbation as defined by Thornton et al. ${ }^{21}$ Exclusion criteria were current severe haemoptysis, rib fractures, pregnancy, inability to give consent and those whose usual ACTwas HFCWO. Informed written consent was obtained for all patients and the study was approved by Brompton Harefield and National Heart and Lung Institute research ethics committee.

\section{Study design}

A randomised crossover design was used to compare HFCWO with patients' usual ACTs, which allowed within-patient variability to be controlled. Over four consecutive days, patients received either HFCWO therapy on days 1 and 3 and their normal ACT on days 2 and 4 or vice versa. Allocation to HFCWO or usual ACT on day 1 was determined using a computer-generated randomisation table.

\section{Protocols}

Patients performed their usual ACT or received HFCWO two times daily at the same time. Before starting the study, each patient's usual ACT was reviewed by an experienced senior respiratory physiotherapist. In addition, patients were familiarised with HFCWO (The Vest). This involved the patients using The Vest for a trial period the day before the start of the study, during which time they were given the opportunity to experience all three protocol frequencies at a variety of pressures. Each airway clearance treatment session lasted $30 \mathrm{~min}$ and was supervised by the same physiotherapist to ensure optimisation and standardisation of usual ACT and HFCWO performance. All nebulised and inhaled medications were taken before each treatment session in accordance with the patients' individual regimens.

\section{High frequency chest wall oscillation}

The following regimen was identified as current best practice following an in-depth review of the literature and discussion with clinical experts in the USA. Using The Vest Airway Clearance System Model 4 (Hill-Rom UK Ltd, Leicestershire, UK), each patient was fitted with an appropriately-sized, full torso, inflatable, disposable vest connected to the air pulse generator via two flexible tubes. Patients remained in an upright sitting position throughout the $30 \mathrm{~min}$ treatment session. HFCWO was applied for $8 \mathrm{~min}$ at each of three frequencies in sequence $(10,13$ and $15 \mathrm{~Hz}$ ) with each frequency followed by a 2 min rest period. The pulse pressure was set according to individual patient's reported comfort at all three frequency settings. During both the HFCWO and rest periods, patients were instructed to huff or cough as they felt necessary in order to expectorate loosened bronchial secretions.

\section{Usual ACT}

Usual ACTs were in accordance with the guidelines of the International Physiotherapy Group for Cystic Fibrosis. ${ }^{22}$ Patients performed their usual ACT for $30 \mathrm{~min}$, and for patients practising an assisted ACT, the physiotherapist provided percussion. Patients were allowed to perform combined ACTs where this was their usual practice. This reflected current international practice more accurately and recommendations that ACTs be adapted on an individual basis. ${ }^{23}$

\section{Outcome measures}

The primary outcome measure was wet weight of sputum expectorated during a treatment session. Patients were instructed to expectorate all sputum into a preweighed pot during and for $30 \mathrm{~min}$ following each treatment session. They were also instructed to collect sputum expectorated at all other times during each $24 \mathrm{~h}$ period. All sputum collected was weighed immediately following collection on weighing scales with an accuracy of $0.01 \mathrm{~g}$ (BL310; Sartorious UK Ltd, Epsom, UK).

$\mathrm{FEV}_{1}$ was measured using a hand-held spirometer (2120; Vitalograph Ltd, Buckingham, UK) in accordance with internationally agreed standards. ${ }^{24}$ Measurements were taken immediately before and after a $30 \mathrm{~min}$ period following each treatment session. Data were analysed using Spirotrac IV Version 4.30 software (Vitalograph Ltd).

Pulsed arterial oxygen saturation $\left(\mathrm{SpO}_{2}\right)$ was measured transcutaneously at rest, for 5 min immediately before, $30 \mathrm{~min}$ during and 30 min immediately following each session. $\mathrm{SpO}_{2}$ was measured with a fingertip pulse oximeter (Konica-Minolta Pulsox-300i; Stowood Scientific Instruments, Oxford, UK). The data were analysed using Download 2001 Version 2.8.0 software (Stowood Scientific Instruments Ltd).

The perceived efficacy and comfort of each ACT and the incidence of urinary leakage during treatment were measured using $10 \mathrm{~cm}$ visual analogue scales (VAS). Each day, after the last treatment session, patients completed three $10 \mathrm{~cm}$ VAS with reference to the ACT used that day. On the VAS used, 0 represented not at all effective/comfortable or no urinary leakage and 10 represented extremely effective/comfortable or a lot of urinary leakage. On the fourth and final day, participants were also asked to indicate which ACT they would prefer.

An independent observer, blind to the daily method of airway clearance used, performed the spirometry, weighed the sputum samples and collected the $10 \mathrm{~cm}$ VAS throughout the study.

\section{Statistical analysis}

A sample size calculation determined the number of patients required to test for superiority of HFCWO. This was based on a difference of $4 \mathrm{~g}$ of sputum between the usual ACT and HFCWO during a single treatment session. A square-root of within SEM of $4 \mathrm{~g}$ at the 5\% significance level would require 24 patients to achieve $90 \%$ power. Data are presented as mean (SD), median (IOR) or $\mathrm{n}(\%)$ as appropriate. Continuous variables were analysed using a mixed-effects linear regression model. This was 
Table 1 Patient demographics and baseline characteristics $(n=29)$

\begin{tabular}{ll}
\hline Age (years) & $29.4(8.4)$ \\
Male $(\%)$ & $21(72 \%)$ \\
Height $(\mathrm{cm})$ & $171(9)$ \\
Weight $(\mathrm{kg})$ & $60(11)$ \\
$\mathrm{BMI}_{\left(\mathrm{kg} / \mathrm{m}^{2}\right)}$ & $20.4(2.6)$ \\
$\mathrm{FEV}_{1}(\mathrm{I})$ & $1.46(0.72)$ \\
$\mathrm{FEV}_{1} \%$ predicted & $38(16.7)$ \\
$\mathrm{SpO}_{2}(\%)$ & $94.3(2.1)$ \\
\hline
\end{tabular}

Data are presented as mean (SD) or $\mathrm{n}(\%)$ as appropriate.BMI, body mass index; $\mathrm{FEV}_{1}$, forced expiratory volume in $1 \mathrm{~s}$; $\mathrm{SpO}_{2}$, pulsed arterial oxygen saturation.

to allow the results to be adjusted for a number of factors which are inherent to the design of a crossover trial. The order of treatment randomisation and the day and time of treatment were all entered into the model and their effect on the outcomes was tested. For this trial, the results were also adjusted for the method and position of treatment in the ACT session. In these models, patients were entered as random effects since it was not of interest to quantify the differences between individual patients, but it was important to account for the repeated measurements on each patient. The estimates of the fixed effect of ACT versus HFCWO are presented as mean (95\% CI). A $\mathrm{p}$ value of 0.05 was taken to be statistically significant. All analyses were conducted using Stata 9.2 (StataCorp).

\section{RESULTS}

\section{Participants}

Fifty patients were invited to participate in the study, 20 declined, 29 patients completed the study and 1 patient was withdrawn due to a hypoglycaemic episode. Table 1 shows demographic and baseline characteristics of the patients who completed the study.

Twenty-nine patients were treated with intravenous antibiotics as part of their medical management. All participants received two treatment sessions on each study day and all treatment sessions were $30 \mathrm{~min}$ in duration. The mean (SD) length of stay for patients was 14 (5) days and the mean day of entry to the study was day 8 (3) days.

\section{Usual ACT}

Usual ACTs included the ACBT with modified PD\&P (41\%; $\mathrm{n}=12)$ and with modified $\mathrm{PD}$ alone $(7 \% ; \mathrm{n}=2), \mathrm{AD}$ in sitting $(28 \% ; n=8)$ and with modified PD $(7 \% ; n=2)$, PEP $(7 \% ; n=2)$ and Flutter $(10 \% ; n=3)$.

\section{Sputum weight}

The wet weight of sputum expectorated with usual ACT compared with HFCWO is shown in table 2 . The mean weight of sputum expectorated during a single treatment session and over a $24 \mathrm{~h}$ period was significantly greater with usual ACT than with HFCWO. The mean difference in wet weight of sputum expectorated during a treatment session was $4.4 \mathrm{~g}(\mathrm{p}<0.001)$ and the mean difference in wet weight of sputum expectorated over a $24 \mathrm{~h}$ period was $6.9 \mathrm{~g}(\mathrm{p}<0.001)$. These findings were not affected by order, time, day or position of treatment.

No statistically significant difference was observed in the amount of sputum expectorated when using HFCWO or usual ACT between treatments in a $24 \mathrm{~h}$ period.

\section{Physiological measures}

$\mathrm{FEV}_{1}$ and $\mathrm{SpO}_{2}$ measured before, during and after usual ACT and HFCWO treatment sessions are shown in table 3.

\section{Comfort, efficacy and preference}

The VAS scores for comfort, efficacy and urinary leakage during usual ACT compared with HFCWO are shown in table 4. No significant differences were observed in VAS scores for comfort or urinary leakage between HFCWO and usual ACT. Patients scored the efficacy of their usual ACT significantly higher than for HFCWO (mean difference $14 \mathrm{~mm} ; \mathrm{p}=0.002$ ). This was not affected by the order or day of treatment. Of those patients who completed the study, 17 (55\%) expressed a preference for their usual ACT over HFCWO. Preference was not predicted by the amount of sputum expectorated.

\section{DISCUSSION}

There have been few published comparisons between HFCWO using a vest system with the ACTs of the ACBT and AD. This short-term study, carried out in individuals with CF admitted to hospital with an acute infective pulmonary exacerbation, showed that significantly more sputum was expectorated during a single treatment session and over a $24 \mathrm{~h}$ period using the patient's usual ACT than with HFCWO. In addition, slightly less sputum was expectorated at all other times (excluding treatment sessions) on usual ACT days compared with HFCWO, but this trend was not statistically significant. These findings were independent of order, time or day and position of treatment. Neither HFCWO nor any of the usual ACTs were associated with any adverse clinical events.

A possible factor contributing to the difference in sputum clearance between HFCWO and usual ACT may have been the number and frequency of forced expiratory manoeuvres (FEMs) and the more gentle expiratory manoeuvres of the $\mathrm{AD}$ breath that were performed with the usual ACTs. Some studies have standardised the number of coughs and FEMs that patients performed; however, at the time of designing the protocol, the aim was to compare the regimens as currently practised internationally and the frequency of coughs and FEMs was neither standardised nor counted. In retrospect, it would have been of value to have counted the number of coughs and FEMs undertaken during each regimen, but it had not been anticipated that

Table 2 Wet weight of sputum expectorated: HFCWO compared with usual ACT

\begin{tabular}{|c|c|c|c|c|c|c|}
\hline \multirow{3}{*}{$\begin{array}{l}\text { Period of sputum } \\
\text { collection }\end{array}$} & \multicolumn{6}{|c|}{ Expectorated sputum wet weight (g) } \\
\hline & \multicolumn{2}{|l|}{ Usual ACT } & \multicolumn{2}{|l|}{ HFCWO } & \multirow[b]{2}{*}{ Mean difference } & \multirow[b]{2}{*}{ p Value } \\
\hline & Mean (SD) & Median (IOR) & Mean (SD) & Median (IOR) & & \\
\hline $24 \mathrm{~h}$ (excluding treatment) ${ }^{*}$ & $22.4(26.8)$ & $12.9(4.0-29.9)$ & $24.9(25.8)$ & $15.3(3.9-40.1)$ & $-1.5(-4.6$ to 1.6$)$ & 0.352 \\
\hline $24 \mathrm{~h}$ (including treatment) & $39.8(36.3)$ & $25.5(14.0-57.1)$ & $34.3(30.7)$ & $26.3(12.1-46.0)$ & 6.9 (3.1 to 10.8$)$ & $<0.001$ \\
\hline
\end{tabular}

Data are presented as mean (SD) or $(95 \% \mathrm{Cl})$ or median (IOR) as appropriate. Data are adjusted for randomisation, day, time and position of treatment using a mixed effects linear regression model.

* Of 116 24-h sputum samples collected, two were discarded as they were incomplete.

ACT, airway clearance technique; HFCWO, high frequency chest wall oscillation. 
Table 3 Forced expiratory volume in $1 \mathrm{~s}$ and pulsed arterial oxygen saturation at baseline, during and after treatment with usual airway clearance technique and HFCWO

\begin{tabular}{|c|c|c|c|c|c|c|}
\hline & \multicolumn{3}{|l|}{ Usual ACT } & \multicolumn{3}{|l|}{ HFCWO } \\
\hline & Baseline & $\begin{array}{l}\text { During } \\
\text { treatment }\end{array}$ & $\begin{array}{l}30 \text { min after } \\
\text { treatment }\end{array}$ & Baseline & $\begin{array}{l}\text { During } \\
\text { treatment }\end{array}$ & $\begin{array}{l}30 \text { min after } \\
\text { treatment }\end{array}$ \\
\hline $\mathrm{FEV}_{1} \%$ predicted & $39.1(16.9)$ & NA & $38.9(17.1)$ & $38.9(16.8)$ & NA & $39.2(16.7)$ \\
\hline $\mathrm{SpO}_{2}(\%)$ & $94.4(2.0)$ & $94.4(1.9)$ & $93.9(1.6)$ & $94.5(1.8)$ & $95.0(1.7)$ & $94.3(1.7)$ \\
\hline
\end{tabular}

Data are presented as mean (SD)

$\mathrm{ACT}$, airway clearance technique; $\mathrm{FEV}_{1}$, forced expiratory volume in $1 \mathrm{~s}$; HFCWO, high frequency chest wall oscillation; $\mathrm{NA}$, not applicable; SpO $\mathrm{H}_{2}$, pulsed arterial oxygen saturation.

any differences between HFCWO and usual ACTs may be a consequence of the number of FEMs or $\mathrm{AD}$ breaths. Theoretically, during the three 8 min periods of HFCWO, fewer FEMs, coughs or $\mathrm{AD}$ breaths would be undertaken than during an equivalent period of the ACBT, AD, PEP or Flutter (all of which inherently include FEMs or $\mathrm{AD}$ breaths at regular intervals). This difference was supported by observations of the investigators. However, manual cough counts are subject to observer error. Objective cough monitoring using the Leicester Cough Monitor has only recently been validated and should be considered for use in further studies. ${ }^{25}$

Components of patient satisfaction include efficacy, comfort and convenience. Some studies have formally evaluated patient satisfaction and compliance. One study reported that $50 \%$ of subjects chose HFCWO compared with the Flutter, and efficacy was the most frequently cited reason for this choice. ${ }^{16}$ A later study reported that HFCWO was not preferred over PD\&P and intrapulmonary percussive ventilation; furthermore, there was no significant correlation between treatment preference and sputum weight. ${ }^{14}$ The current study found that patients perceived the efficacy of HFCWO to be statistically significantly less than that of their usual ACT. However, nearly half (45\%) of patients expressed a preference for HFCWO. Preference may have been affected by the novelty of a new treatment and it is unknown whether this would continue in the long term.

There is no one recommended protocol for the application of HFCWO in the literature. Published studies describe differing numbers and duration of frequencies, length of treatment and airway clearance. Frequencies of 10, 13 and $15 \mathrm{~Hz}$ were chosen as it has been reported that maximum mucus transport occurs between 11 and $15 \mathrm{~Hz}$ with a peak at $13 \mathrm{~Hz} .{ }^{5}$ In addition, the highest oscillated tidal volume flow (peak airflow) occurred between 10 and $15 \mathrm{~Hz}$ in patients with $\mathrm{CF}^{26}$ More recent research recommends an individual "tuning" method to identify optimum treatment frequencies. These have been shown to vary among individuals and the oscillation waveform, ${ }^{27}$ but it is unknown whether "tuning" increases efficacy.

It is possible that a practice effect could have occurred as all patients were new to HFCWO. However, the protocol used in this study did not require the patient to perform any newly learnt physical technique. In addition, the statistical analysis ensured data were adjusted for day of treatment and found no

Table 4 Comfort, efficacy and urinary leakage: HFCWO compared with usual ACT

\begin{tabular}{lcccc}
\hline \multirow{2}{*}{$\begin{array}{l}\text { Self reported } \\
\text { measure }\end{array}$} & \multicolumn{4}{l}{ Visual analogue scale score $(\mathbf{m m})$} \\
\cline { 2 - 5 } & Usual ACT & HFCW0 & Mean difference & p Value \\
\hline Comfort & $69(23)$ & $70(22)$ & $-1(-9$ to 7$)$ & 0.784 \\
Efficacy & $68(21)$ & $54(26)$ & $14(6$ to 23$)$ & 0.002 \\
Urinary leakage & $0(1)$ & $0(1)$ & $-0.05(-0.3$ to 0.4$)$ & 0.791 \\
\hline
\end{tabular}

Data are presented as mean (SD) or $(95 \% \mathrm{Cl})$ as appropriate. Data are adjusted for randomisation, day of treatment and time of treatment using a mixed effects linear regression model.

ACT, airway clearance technique; HFCWO, high frequency chest wall oscillation. effect. Alternatively, patients' familiarity with their usual ACT may also have had an effect on outcomes.

This study was powered to detect a difference of $4 \mathrm{~g}$ of sputum expectorated during a single treatment session. Other studies have been based on a difference of $3-3.5 \mathrm{~g}$, which is generally accepted as a clinically important difference. ${ }^{28} 29$ Wet weight sputum was felt to be an appropriate primary outcome measure in this short-term study in an acute environment. Previous work has found wet weight to be proportional to dry weight sputum. ${ }^{28}{ }^{30}$ Emerging non-invasive means of measuring airway clearance may be more sensitive indicators in the future (eg, lung clearance index and electrical impedance tomography).

Considering the cost benefit of HFCWO compared with other ACTs and the differing healthcare systems in the USA and the UK, it is unlikely that HFCWO will become the first choice ACT for most individuals in the UK. Further work needs to be undertaken to identify the place of HFCWO in Europe. Patient preference for a treatment regimen may positively influence adherence to treatment in the short term, and nearly half the patients who participated in this study preferred HFCWO to their usual ACT. HFCWO is a safe treatment that facilitates airway clearance in CF but, when compared with patients' usual ACTs, HFCWO led to the clearance of significantly less sputum during a single treatment session and over a $24 \mathrm{~h}$ period.

Acknowledgements The authors wish to thank the patients who participated in the study and members of the Physiotherapy Department at Royal Brompton Hospital, London, UK and Catherine Sandsund who acted as independent observers.

Hill-Rom did not participate in the design of this study, the collection, analysis and interpretation of data or in writing the manuscript.

Funding A grant from the Robert Luff Foundation funded the lead researcher's post. Hill-Rom kindly provided two high-frequency chest wall oscillators (the Vest), disposable vests and tubes, two pulse oximeters and a spirometer for use in this study.

Competing interests $\mathrm{LO}$ received reimbursement of registration, travel and accommodation expenses for attendance at the 20th North American Cystic Fibrosis Conference and an honorarium for speaking at a national workshop organised by Hill-Rom.

Ethics approval Ethical approval was obtained from Brompton Harefield and National Heart and Lung Institute research ethics committee.

Provenance and peer review Not commissioned; externally peer reviewed.

\section{REFERENCES}

1. Dodge JA, Lewis PA, Stanton M, et al. Cystic fibrosis mortality and survival in the UK 1947-2003. Eur Respir J 2007:29:522-6.

2. UK CF Database. Cystic fibrosis trust annual data report 2004. http://www.cftrust org.uk: Cystic Fibrosis Trust, 2006

3. Coakley RD, Boucher RC. Pathophysiology: epithelial cell biology and ion channel function in the lung, sweat gland and pancreas. In: Hodson M, Geddes D, Bush A, eds. Cystic fibrosis. 3rd edn. London: Hodder Arnold, 2007;59-68.

4. Association of Chartered Physiotherapists in Cystic Fibrosis. Clinical guidelines for the physiotherapy management of cystic fibrosis: recommendations of a working group. http://www.cftrust.org.uk: Cystic Fibrosis Trust, 2002.

5. Gross D, Zidulka A, O'Brien C, et al. Peripheral mucociliary clearance with highfrequency chest wall compression. J Appl Physiol 1985;58:1157-63.

6. King M, Phillips DM, Gross D, et al. Enhanced tracheal mucus clearance with high frequency chest wall compression. Am Rev Respir Dis 1983;128:511-15. 
7. Hansen LG, Warwick WJ, Hansen KL. Mucus transport mechanisms in relation to the effect of high frequency chest compression (HFCC) on mucus clearance. Pediatr Pulmonol 1994;17:113-18.

8. Braggion C, Cappelletti LM, Cornacchia M, et al. Short-term effects of three chest physiotherapy regimens in patients hospitalized for pulmonary exacerbations of cystic fibrosis: a cross-over randomized study. Pediatr Pulmonol 1995;19:16-22.

9. Hansen LG, Warwick WJ. High-frequency chest compression system to aid in clearance of mucus from the lung. Biomed Instrum Technol 1990:24:289-94

10. Kluft J, Beker $L$, Castagnino $M$, et al. A comparison of bronchial drainage treatments in cystic fibrosis. Pediatr Pulmonol 1996;22:271-4.

11. Warwick WJ, Wielinski CL, Hansen LG. Comparison of expectorated sputum after manual chest physical therapy and high-frequency chest compression. Biomed Instrum Technol 2004;38:470-5.

12. Arens R, Gozal D, Omlin KJ, et al. Comparison of high frequency chest compression and conventional chest physiotherapy in hospitalized patients with cystic fibrosis. Am J Respir Crit Care Med 1994;150:1154-7.

13. Scherer TA, Barandun J, Martinez E, et al. Effect of high-frequency oral airway and chest wall oscillation and conventional chest physical therapy on expectoration in patients with stable cystic fibrosis. Chest 1998;113:1019-27

14. Varekojis SM, Douce FH, Flucke RL, et al. A comparison of the therapeutic effectiveness of and preference for postural drainage and percussion, intrapulmonary percussive ventilation, and high-frequency chest wall compression in hospitalized cystic fibrosis patients. Respir Care 2003:48:24-8.

15. Darbee JC, Kanga JF, Ohtake PJ. Physiologic evidence for high-frequency chest wall oscillation and positive expiratory pressure breathing in hospitalized subjects with cystic fibrosis. Phys Ther 2005;85:1278-89.

16. Oermann CM, Sockrider MM, Giles D, et al. Comparison of high-frequency chest wall oscillation and oscillating positive expiratory pressure in the home management of cystic fibrosis: a pilot study. Pediatr Pulmonol 2001;32:372-7.

17. Warwick WJ, Hansen LG. The long-term effect of high-frequency chest compression therapy on pulmonary complications of cystic fibrosis. Pediatr Pulmonol 1991:11:265-71.
18. Phillips GE, Pike SE, Jaffe A, et al. Comparison of active cycle of breathing and highfrequency oscillation jacket in children with cystic fibrosis. Pediatr Pulmonol 2004:37:71-5

19. Bradley JM, Moran FM, Elborn JS. Evidence for physical therapies (airway clearance and physical training) in cystic fibrosis: an overview of five Cochrane systematic reviews. Respir Med 2006;100:191-201.

20. Rowe SM, Clancy JP. Advances in cystic fibrosis therapies. Curr Opin Pediatr 2006;18:604-13

21. Thornton J, Elliott R, Tully MP, et al. Long term clinical outcome of home and hospita intravenous antibiotic treatment in adults with cystic fibrosis. Thorax 2004;59:242-6.

22. International Physiotherapy Group for Cystic Fibrosis. Physiotherapy in the treatment of cystic fibrosis (CF). 3rd edn. www.cfww.org/ipg-cf/?article=195.

23. Lapin C, Lapin A, Pryor JA. Physiotherapy. In: Hodson M, Geddes D, Bush A, eds. Cystic fibrosis. 3rd edn. London: Hodder Arnold, 2007;407-20.

24. Miller MR, Hankinson J, Brusasco V, et al. Standardisation of spirometry. Eur Respir J 2005;26:319-38

25. Birring SS, Fleming T, Matos S, et al. The Leicester Cough Monitor: preliminary validation of an automated cough detection system in chronic cough. Eur Respir J 2008;31:1013-18.

26. Jones RL, Lester RT, Brown NE. Effects of high frequency chest compression on respiratory system mechanics in normal subjects and cystic fibrosis patients. Can Respir J 1995;2:40-6.

27. Milla CE, Hansen LG, Warwick WJ. Different frequencies should be prescribed for different high frequency chest compression machines. Biomed Instrum Technol 2006; 40:319-24.

28. Cecins NM, Jenkins SC, Pengelley J, et al. The active cycle of breathing techniques - to tip or not to tip? Respir Med 1999;93:660-5

29. Patterson JE, Bradley JM, Elborn JS. Airway clearance in bronchiectasis: a randomized crossover trial of active cycle of breathing techniques (incorporating postural drainage and vibration) versus test of incremental respiratory endurance. Chron Respir Dis 2004:1:127-30.

30. Sutton PP, Parker RA, Webber BA, et al. Assessment of the forced expiration technique, postural drainage and directed coughing in chest physiotherapy. Eur J Respir Dis 1983; 64:62-8.

\section{Lung alert}

\section{Higher mortality from non-small cell lung cancer reported in subjects treated with oestrogen and progestin}

The Women's Heath Initiative (WHI) trial was a double-blind randomised placebo-controlled trial that examined the health benefits and risks of combined oestrogen and progestin in 16608 postmenopausal women in the USA. The study was stopped early as health risks were shown to exceed benefits. In this study, both the incidence and mortality from lung cancer during the treatment and follow-up phases of the WHI (mean 7.9 years) were determined in a posthoc analysis.

No statistically significant differences in the incidence of lung cancer were seen between active ( $n=109)$ and placebo $(n=85)$ groups (incidence $0.16 \%$ vs $0.13 \%$; HR $1.23,95 \%$ CI 0.92 to 1.63). More women died from lung cancer in the active $(n=73)$ compared with the placebo $(\mathrm{n}=40)$ groups, and more deaths were seen in non-small cell lung cancer in the active ( $\mathrm{n}=62$; $0.09 \%)$ compared with the placebo $(n=31 ; 0.05 \%)$ groups. There were no statistically significant differences in deaths from small cell lung cancer in the active $(n=11 ; 0.02 \%)$ compared with the placebo $(\mathrm{n}=9 ; 0.01 \%)$ group.

Although there was no increase in the incidence of lung cancer in those on combined treatment, there was an increase in deaths attributable to lung cancer, especially in non-small cell disease. The authors speculate that combined hormone therapy stimulates growth of existing non-small cell lung cancers. This should be discussed with women considering combined hormone therapy, in particular those in a high-risk group.

- Chlebowski RT, Schwartz AG, Wakelee H, et al, for the Women's Health Initiative Investigators. Oestrogen plus progestin and lung cancer in postmenopausal women (Women's Health Initiative trial): a post-hoc analysis of a randomised controlled trial. Lancet 2009;374:1243-51.

\section{P A Marsden}

Correspondence to P A Marsden, ST3 Respiratory Medicine, Blackpool Victoria Hospital, UK; Paul.A.Marsden@manchester.ac.uk

Thorax 2010:65:200. doi:10.1136/thx.2009.134809 